\title{
Sources, Outcomes, and Resolution of Conflicts in Marriage among Iranian women: A qualitative study
}

Zahra Sadat Asadi ${ }^{1}$, Roya Sadeghi², Mohammad Hossein Taghdisi ${ }^{3}$, Freshteh Zamani-Alavijeh ${ }^{4}$, Davoud Shojaeizadeh $^{5}$, Ali Reza Khoshdel ${ }^{6}$

${ }^{1}$ Ph.D. Candidate of Health Education \& Promotion, Department of Health Promotion, Tehran University of Medical Sciences, Tehran, Iran

${ }^{2}$ Ph.D. in Health Promotion, Associate Professor, Department of Health Promotion, Tehran University of Medical Sciences, Tehran, Iran

${ }^{3}$ Professor, Research Council Member of Center for Community Based Participatory Research, Health Education and Promotion Department, School of Public Health, Iran University of Medical Sciences, Tehran, Iran

${ }^{4}$ Ph.D., Associate Professor, Department of Health Education and Promotion, School of Health, Isfahan University of Medical Sciences, Isfahan, Iran

${ }^{5}$ Ph.D. in Health Promotion, Professor, Department of Health Promotion, Tehran University of Medical Sciences, Tehran, Iran

${ }^{6}$ MD-Ph.D., Associate Professor, Department of Epidemiology, School of Medicine, Aja University of Medical Sciences, Tehran, Iran

\section{Type of article: Original}

\begin{abstract}
Introduction: Family's conflict is the important determinant of the quality and quantity of relationships among family members. No study of which we are aware has assessed conflicts, especially among normal or apparently satisfied couples in the Iranian context. This study explored that how women deal with different points, ideas and behaviors in marital life.

Methods: For the study, we recruited 30 to 45 -year-old housewives who visited health centers in Tehran, Iran. The participants $(\mathrm{n}=45)$ were selected using purposefully convenient sampling. In-depth interviews and focus group discussions were used. The data were analyzed qualitatively using MAXQDA 10.

Results: Themes, including conflicting situations, causes of conflict, consequences of conflict, and conflict resolution styles were extracted.

Conclusion: Although Iranian women were dissatisfied with their lives, they tried to protect their marriages.

Keywords: conflict, marriage, qualitative study
\end{abstract}

\section{Introduction}

Conflicts are among the most important determinants of the quantity and quality of relationships among family members (1). "When family members believe that what they want is incompatible with what one or more other families want, conflict happens" (2). In fact, conflicts are caused by inconsistent goals or interests of family members and their different evaluations of life issues (1). Research conducted in Iran and other countries have shown that conflicts are common between couples, and, in Iran, $92 \%$ of the respondents reported conflicts in their marriages (3). Studies from other parts of the world also have indicated conflicts and minor abuse among $65 \%$ of the women $(4,5)$. Conflicts are necessary and valuable for the evolution of a marriage (6). Conflicts that are properly managed can help couples learn from each other and improve their relationships (7). Conflicts in marriages may produce various personal, familial, physical, and psychological consequences (8). They can result in depression (9), anxiety, and eating disorders $(8,10)$. Despite the fact that married people are usually healthier than single people $(10,11)$, conflicts in marriages can lead to poorer health conditions (11) and the risk of certain diseases, such as

\section{Corresponding author:}

Associate Professor Dr. Roya Sadeghi, Department of Health Promotion, Tehran University of Medical Sciences, Tehran, Iran. E-mail: sadeghi_roya@yahoo.co.uk

Received: November 23, 2015, Accepted: January 14, 2016, Published: March 2016

iThenticate screening: January 13, 2016, English editing: January 27, 2016, Quality control: February 03, 2016

(C) 2016 The Authors. This is an open access article under the terms of the Creative Commons Attribution-NonCommercialNoDerivs License, which permits use and distribution in any medium, provided the original work is properly cited, the use is non-commercial and no modifications or adaptations are made. 
heart disease $(11,12)$, as well as cancer and chronic pains (10). Furthermore, conflicts in marriages can affect family life in different ways, e.g., it may decrease the performance of the parents and the compatibility of the children and increase conflicts among all family members (parents and children as well as between siblings) (1). Evaluation of the effects of conflicts in marriages on the physical and psychosocial health of children has indicated that such conflicts adversely affected the emotional safety of children (12). In general, such conflicts exert negative effects on the children and result in their insecure attachment to parents $(1,10,12)$. Various sources, such as incompatible needs of couples, poor communication skills, distorted beliefs, extreme emotional reactions, and negative enforcing patterns can trigger conflicts in marriages (13). Researchers also have identified several major sources of conflict, i.e., violent behaviors of husbands, lack of cooperation in the family, inability to spend enough time together, issues related to children and other families, lack of effective communication, and financial problems (14). Indian women considered low interaction with their husbands, gender preferences, and alcohol abuse to be responsible for their low-quality communication with their husbands. Women also expressed fear, anxiety, depression, and nervousness about becoming mothers due to the pressure to have a son at all costs and families' rejection of a female child, and alcohol abuse as the main factors responsible for their low-quality communication with their husbands (15). Also, a quantitative study of couples highlighted personal traits, communication skills, commitment, and family background as the most significant factors related to conflicts in marriages (16). In a study of the effects of family therapy on resolving family conflicts, Kumar concluded that family therapy was effective for social and psychological problemsolving, promoted effective involvement of family members, and improved the family members' social and psychological performance, healthy communication patterns, and satisfaction in relationships (17). Dildar investigated conflict resolution methods among unhappily married couples and suggested that both parties tended to use avoidance techniques to resolve conflicts, i.e., they have not used compromise, collaboration, or forgiveness methods (14). Moreover, the dominant style occurred more frequently among men than women (14). In a quantitative study, the effectiveness of solution-focused couples' therapy on dimensions of intimacy among couples was assessed in Isfahan, Iran. It was reported that this method could efficiently enhance intimacy in couples with problematic marriages (18). In a quantitative study, acceptance and commitment therapy also was found to have increased intimacy and decreased conflicts among couples in Tehran, Iran (19). Also, quantitative results have shown that training couples in communication skills and conflict resolution styles has been successful in increasing satisfaction and decreasing conflicts $(20,21)$, and significant differences have been identified in neuroticism, openness, conscientiousness, and all subscales of the psychological symptoms list between normal and high-risk (divorcing) couples. Moreover, from all personal, psychological, and demographic variables, neuroticism, depression, paranoia, number of children, type of marriage, and household income were significantly associated with marital conflicts. Heydari and his colleague confirmed that effective dialogue could efficiently decrease conflicts in marriage, and they suggested that emotional reactions toward each other, attracting children's support, collaboration, and sexual relationships were the main factors that affect the quality of a marriage (23). Also, Mohsenzade and his colleague categorized the factors that lead to marital dissatisfaction and divorce as pre-marriage factors (including forced marriage, marriage with inappropriate incentives, e.g., undesirable living conditions and avoiding social pressures caused by being single) and post-marriage factors (such as conflicts with in-laws, absence of the spouse, continuing the previous lifestyle, conflicts about sexual roles, marital violence, distrust, and financial problems). Moreover, in this qualitative study of couples, divorce was found to be the result of four major factors, i.e., drug addiction, betrayal, violence, and severe conflicts with in-laws (24). Navidian studied divorcing couples and detected positive correlations between family conflicts and avoidance and competition styles; he also found conflicts in marriages to be negatively correlated with reconciliation and collaboration conflict resolution styles, and he concluded that women tended to use accommodation styles and men preferred accommodation and collaboration styles (25). Previous studies in Iran have focused mainly on quantitative studies of family violence and developing and testing interventions in dissatisfied, divorcing, or divorced couples. However, marital conflicts in the Iranian context, especially among normal or apparently satisfied couples, have been neglected. However, we hypothesized that Iranian women were truly concerned about protecting their marriages and improving their relationships with their spouses, so they may just pretend to be happy. Therefore, to clarify the concept of conflicts in the traditional Iranian context (particularly in Tehran) using a qualitative design, the present study sought to answer the following questions:

1) What are the sources of conflict with their spouse from the viewpoint of married women?

2) How can a marriage be affected by conflicts with the spouse?

3) What mechanisms are used to resolve conflicts and problems? 


\section{Material and Methods}

\subsection{Participants}

This study was conducted in the eastern part of Tehran (including the $8^{\text {th }}$ and $13-15^{\text {th }}$ districts of the city). In each district, one or two health centers were selected randomly. The inclusion criteria were the age range of 30-45, no history of divorce, being the only wife of one's husband, and willingness to participate. Women who were treated at the selected health centers were recruited using purposeful convenience sampling. In each health center, explanations were given to women regarding the study's objectives and procedures; they also were invited to participate using the information boards of health centers and through text messages sent to their cell phones. Ultimately, data collected from 45 women from all of the health centers were analyzed qualitatively (due to data saturation). All of the women who participated signed an informed consent form before their participation began.

\subsection{Data collection}

After the study protocol was approved by the Tehran University of Medical Sciences and relevant municipalities, the data were collected through seven in-depth interviews and four focus group discussions, which were scheduled based on the participants' preferences. The focus group discussions (with about 7 to 10 women per group) and indepth individual interviews were conducted in quiet and relatively private places. The interviews and focus groups were conducted by a trained expert using semi-structured questions. They began with a general request ("Tell me how you started your day") followed by semi-structured questions, such as "Can you explain more about your relationship with your husband?", "What makes you less satisfied in your relationship with your husband?", and "How do you deal with differences in points, ideas, and behaviors in your marital life?". The total duration of every individual and focus group ranged from 45 to 120 minutes. The women were invited to focus groups and interviews until data saturation was achieved. The data collection and analysis procedures were conducted during the period from July 2013 to July 2014.

\subsection{Data analysis}

In this exploratory study, the data were analyzed using the Strauss and Corbin Method of content analysis (26). Both inductive and deductive approaches were applied to analyze the data. The interviews were recorded and transcribed verbatim, and field notes were completed immediately after each interview. Then, the interviews were read several times, and the main concepts were extracted. First, open coding was used, which means "the analytical process through which concepts are identified and their properties and dimensions are discovered in data" (26), and the transcription was understood through line-by-line coding, sentence-by-sentence to develop categories. After that, we did Axial coding to relate subcategories to each major category (26), and then we compared the codes to identify similarities and differences. Then, we tested the concepts and categories with literature reviews. In this latter stage, the categories that were most relevant to the research questions were noted (27). Therefore, the main themes were organized according to the research questions. In the current research, all of the coding was performed by one unique coder. However, to evaluate the trustworthiness of the coding, some random parts of the transcripts were coded by two other coders. The validity of the data was assessed through the method suggested by Lincoln and Guba (28). Moreover, to ensure the accuracy of the transcripts of the interviews, they were reviewed and confirmed by the participants. The research team reviewed all of the interviews and codes thoroughly to determine the existing agreements and divergences. To check the confirmability of the data and codes, they were reviewed and approved by a team of experts (not involved in the data collection or the analyses). A review of the related literature also was conducted with the same purpose. As a result, first, the concepts and codes were extracted and examined using reflexive texts (journals). Then, they were sent to several experts to confirm the final codes (confirmability audit). To examine the dependability of the data, the interviews were sent to several qualitative research experts who coded some parts of the interviews independently from the study coder to try to achieve maximum dependability of data. Finally, the direct quoting technique and examples were used to enhance the fitness or transferability of the data (28). Qualitative data were analyzed with MAXQDA 10 for Windows (VERBI GmbH, Berlin, Germany). Also SPSS16 was used to describe the demographic factors.

\section{Results}

The demographic characteristics of the participants are presented in Table 1. Overall, four themes (or main categories) were extracted from the statements of the women, and the themes were conflicting situations, consequences of conflicts, causes of conflict, and conflict resolution styles (Table 2). 
Table 1. Demographic characteristics of women participating in individual interviews and focus group discussions $(\mathrm{N}=45)$

\begin{tabular}{|c|c|c|}
\hline \multicolumn{2}{|l|}{ Variable } & Numerical findings \\
\hline \multicolumn{2}{|l|}{ Age (years); mean (SD) } & $37(5.52)$ \\
\hline \multicolumn{2}{|c|}{ Number of children; mean (SD) } & $1.6(0.61)$ \\
\hline \multicolumn{2}{|c|}{ Duration of marriage (years); mean (SD) } & $13.26(4.78)$ \\
\hline \multirow[t]{4}{*}{ Education; n (\%) } & Elementary school & $1(2.2)$ \\
\hline & Junior high school & $5(11.1)$ \\
\hline & High school diploma & $30(66.7)$ \\
\hline & University degree & $9(20)$ \\
\hline \multirow[t]{2}{*}{ Husband's job; n (\%) } & Public sector & $11(24.4)$ \\
\hline & Private sector & $34(75.6)$ \\
\hline
\end{tabular}

Table 2. Summary of themes and categories and some of the codes extracted from interviews with women $(\mathrm{n}=45)$

\begin{tabular}{|c|c|c|}
\hline Themes & Categories & Subcategory \\
\hline \multirow[t]{4}{*}{$\begin{array}{l}\text { Conflicting } \\
\text { situations }\end{array}$} & Emotional conflict & $\begin{array}{l}\text { Lack of respect for each other's freedom; Not appreciating the } \\
\text { wife (mother) in the family }\end{array}$ \\
\hline & Cognitive conflict & Distrust in the husband in terms of having an affair \\
\hline & Negotiation conflict & Limited conversation; Using improper phrases by the husband \\
\hline & Behavioral conflict & $\begin{array}{l}\text { Husband's lack of contribution in home issues; Husbands' } \\
\text { neglect of women's needs; Secret life (hiding things from each } \\
\text { other); Husband's tendency to spend much time with his friends; } \\
\text { Conflict of sexual relations }\end{array}$ \\
\hline \multirow{2}{*}{$\begin{array}{l}\text { Consequences of } \\
\text { conflict }\end{array}$} & Social consequences & Lower tendency to socialize with family and friends \\
\hline & $\begin{array}{l}\text { Personal } \\
\text { consequences }\end{array}$ & Psychological consequences; Physical consequences \\
\hline \multirow[t]{4}{*}{ Causes of conflict } & Emotional reasons & $\begin{array}{l}\text { Fatigue due to overwork; Previous unsuccessful experiences; } \\
\text { Lack of independence; Unwillingness of men to do women's } \\
\text { favorite activities; Husbands' lack of understanding of women's } \\
\text { physical conditions; Inability to socialize with family }\end{array}$ \\
\hline & Cognitive reasons & Husband's beliefs; Different viewpoints and priorities of couples \\
\hline & $\begin{array}{l}\text { The role of } \\
\text { significant others }\end{array}$ & $\begin{array}{l}\text { Difference in communication patterns of the husband and wife's } \\
\text { families; The role of influential people in their life }\end{array}$ \\
\hline & Background causes & Difference in education; Husband's personality features \\
\hline \multirow{4}{*}{$\begin{array}{l}\text { Conflict } \\
\text { resolution styles }\end{array}$} & Interactive behaviors & Counseling; Conversation \\
\hline & Dominance & Aggression; Reaction in the fights; Verbal dispute; Retaliation \\
\hline & $\begin{array}{l}\text { Accepting the } \\
\text { situation }\end{array}$ & $\begin{array}{l}\text { Respecting husband's family; Paying attention to husband's } \\
\text { personality; Loving the husband }\end{array}$ \\
\hline & $\begin{array}{l}\text { Indifference and } \\
\text { avoidance }\end{array}$ & $\begin{array}{l}\text { Indifference to husband's reactions; Avoiding conversations; } \\
\text { Self-satisfaction }\end{array}$ \\
\hline
\end{tabular}

\subsection{First theme: Conflicting situations}

Although the women appeared to have happy lives, their relationships and conflicts with their husbands were their common concerns (actually one of the obsessions of these Iranian women). This main theme had the following subthemes:

3.1.1. Emotional conflict

Most women complained about their family's lack of appreciation and respect. They wanted to be appreciated even with a word or look. "Most women sacrifice... they expect their men to thank them with just a look or a word! No one wants a gift or things like that, just a look and a small talk to show that I understand you are working hard, or I know you did something", Nastaran (33 years old) in focus group discussions.

3.1.2. Negotiation conflict

Many participants mentioned their husband's lack of respect (e.g., using improper words and phrases) during arguments. "He doesn't like that I'm fat. Sometimes, he insults me in our fights and blames me with dirty words. It is not appropriate to say them" Marjan (33 years old). 


\subsubsection{Behavioral conflict}

Most of the participating housewives believed that their husbands neglected their needs and demands, e.g., they did not allow their wives to do their favorite activities or asked them to quit their jobs and other social activities. "It was so hard to quit my job and stay home after four or five years of working... I did that about eight-nine years ago... I worked in Ameneh Nursery... My husband wanted this and he didn't tell me this before our marriage." Marjan (33 years old). Some of the participants also considered their husband's decision on what they wore as another sign of ignoring their own wishes. “...He told me he didn't like me to wear jeans. Then he said no colorful shoes, bags, or scarves! I have to wear it all black from head to toes. If I am lucky and have the chance to wear another color, it should be navy blue or brown. I was a 22 -year-old girl when I got married. I tolerated everything. " Maryamm (30 years old). Ignoring women's success and humiliating them was another example of men's neglect of their wives' wishes. “...I told my husband I wanted to get my driver's license. .... He made fun of me and laughed at me. He said even if I got a driver's license, he wouldn't let me drive! I got my license ... I happily called him, but he said: "Congratulations and throw it away!" Maryamm (30 years old). A few of our participants suggested their husband's lack of commitment to their marriages (e.g., spending too much time with their friends and devoting holidays to activities with their friends and without their wives) as another factor contributing to conflicting situations. "Fridays (weekend in Iran)... He goes out at 10:00 or 11:00 a.m. and comes back at 5.00! Then he says he's been to the market to buy this and that. I was with my friends!?... Sometimes I'm out and when I come back with an excuse I see his friends in the house. They are men. But I don't like other men to come to my house when I'm not home! But he keeps saying they are his friends" Marjan (33 years old). Secrecy and hiding things from each other also was identified as a conflicting situation in marital life. "They say they had bought something for 25,000 Tomans. Meanwhile, they actually bought it for 20,000 Tomans! This is secrecy! Or my husband didn't like me to take a swimming course... I asked him how long I had to wait for something both legal and conventional? Then I went to a swimming course in the summer and hid it from him." Maryamm (30 years old) "He deals in secrecy and he works in secrecy! He buys a house secretly and registers it in his mother's name ...But this behavior, bothers me" she added about her husband's secrecy.

\subsection{Second theme: Consequences of conflicts}

The following subthemes comprised this main theme:

3.2.1. Personal consequences

This subtheme included psychological and physical consequences. Feelings of humiliation and anger, forgetfulness, mood swings, and physical exhaustion were repeatedly reported by women. "Everything is wiped off my mind! Even for an ordinary conversation.... I had a job, and I got retired. Since then, my husband doesn't let me move" Shahrzad (42 years old). "I usually say that in over 20 years of life, I have done everything. Now, my grandchildren have come, you know, sometimes the pressure of work is so much that I ask very little things like picking up the tablecloth from them. They even do this reluctantly. .. Now, I'm not as strong as before... If they help me, I will be under less pressure. I will have a healthier ..., when children return to their homes at night, I have nausea because of fatigue. These make my body drop. Mahtab (44 years old).

3.2.2. Social consequences

The main social consequence of conflicts was lower tendency to socialize with family and friends. “... He didn't let me go to relatives' houses. He said they could visit us, but I couldn't go. ..My friends always complained they were coming to my house all the time and that I never went to theirs... I called them and said my husband didn't allow me to go to their houses. They then said that he certainly did not like our friendship and our visiting each other. This happened to my friends, my family, and relatives. He did the same to many relatives: to my aunt, my uncle, and... Then he asked them to come. It is not logical..." Maryamm (30 years old).

\subsection{Third theme: Causes of conflict}

\subsubsection{Cognitive reasons}

Most of the participants considered different priorities and interests of the couples as the most important cause of conflict. Different viewpoints of men and women about their life affairs were cited as examples. "He says it makes us closer when I ask him to help around the house. But I say he knows how I am! For example ... these beds ... I told him he saw how heavy they were, he saw the beds were heavy and I was moving them from this house to the other one so we could paint. He said why I didn't ask him to help!!! ... He got angry and said I couldn't do it alone..." Maryam (35 years old). Most of the participants also believed that men valued tasks differently. "I had a present for my husband on Men's Day, but he never gives me one, not for my birthday, not our anniversary. I reminded him but he never did...." Fatemeh (40 years old). 


\subsubsection{The role of significant others}

Many interviewees highlighted the roles of others, especially mothers-in-law and fathers-in-law, in the development of conflicts. These women believed that their everyday life was disturbed by their parents-in-law. "We were going out with our son. Suddenly, my father-in-law came and we had to stay home that day" Mahsa (45 years old). They also complained about the interference of their in-laws in their decision making."...I did not think about showing an unimportant powder formulation that I had bought for my skin to my mother-in-law. ... my husband got angry and fought with me about why I had not shown the formulation to him! I was shocked! I said I didn't know ....He said I had to show whatever we had to his mother. Well, then I showed it to him" Maryamm (30 years old). "Although we live far from my in-laws, they decide for us: where we should go and where we shouldn't, which aunt or uncle we should visit,...when we visited there, we were not allowed to say hello when we saw this uncle or we had to change our way when he was passing." Nataran (33 years old).

\subsection{Fourth theme: Conflict resolution styles}

Conflict resolution styles were classified in the following four categories:

3.4.1. Interactive behaviors

Many women in our study who were also in unsatisfactory marital situations tried to use interactive strategies, such as counseling or having a conversation with each other. "We even visited a psychiatrist to receive help. He told my husband that he had do to some stuff, that he had to allocate part of his income to my needs as he promised the first day... . But he didn't" Maryamm (30 years old). Conversation also was used as a technique to deal with conflicts by many of the interviewees. "We spoke at the beginning of our marriage and promised to discuss our problems any time one of us gets upset. We never argue; we convince each other. He'd explain this and that." Mahbanoo (45 years old). "If I have something to do or I need to go somewhere, I discuss it with my husband.." Tayyabeh (44 years old). 3.4.2. Indifference and avoidance

Avoiding and not facing each other was mentioned as another mechanism for resolving conflicts. It included avoiding conversations; becoming indifferent to spouse's reactions, and trying to please oneself. "I do whatever I like. ... Yeah, he has reactions such as getting angry, but I don't care at all ... yeah it creates tension, but my mind has changed. I'm no longer the girl I used to be 10-12 years ago when I married him." Maryamm (30 years old). "It's been a while since I don't care anymore. I tell him I'm going out...." Shahrzad (45 years old). "When my husband is in the mood, he keeps silent and does not answer me when I ask him why he is late" Marjan (33 years old).

\subsubsection{Dominance}

Other behaviors were placed in the dominance category, such as aggression, retaliation, fighting back, and verbal disputes. Women who used this style sought revenge for the undesirable behaviors of their husbands. "... When he hides his works from me, I hide many things from him, too... You know, it is too bad when you don't trust your life partner. But this way I act like him" Maryamm (30 years old). Another mechanism in this category was verbal dispute, i.e., using inappropriate words and language. "When they come home in the evening and dinner is ready, it doesn't matter at all. But if there is no dinner, they say you are always sick" Mitra (35 years old). "But I do not loose myself. I say if someone does not like me, he can look elsewhere.” Marjan (33 years old).

3.4.4. Accepting the situation

The last conflict resolution style was accepting the situation. It relates to cases when one of the dissatisfied parties tries to soften the situation for any reason. These cases included paying attention to the husband's personality, loving the husband, and respecting the husband's family. For instance, Maryam (35 years old) suggested paying attention to her husband's personality as an effective factor in reducing their conflicts. "If I wake up in the morning and get angry, as soon as I see my husband's clothes on the chair, I'd get angrier by continuously thinking about this. But if I say it is his habit, I can adapt myself to this situation..." Some participants also highlighted the importance of being kind and loving towards their husbands in resolving conflicts. "They (men) just want a woman who is their queen and this queen does not continually question them. She makes tea or massages him. This way, our problems easily solved and it's better than asking what happened and what's wrong with you." Mahin (40 years old).

\section{Discussion}

Our study participants regarded behavioral conflicts, especially men's neglect of women's desires and needs and excessive demands, as the most important causes of conflicts in marriages. This finding was expected, considering the cultural and traditional context of Iran, which presumes men as the rulers and decision makers in the family. Several previous studies also have underscored the influential roles of our patriarchal culture in family environments $(14,29,30)$. The Iranian women who participated in our study also reported negotiation conflict as another manifestation of conflicts. They believed that, under undesirable life conditions, their husbands used improper 
phrases to address them. Although these men may not really have meant to insult or raise conflicts by using such language, they annoy and irritate their wives who ask for a better life. All women in a similar Japanese study reported emotional abuse (30). It is noteworthy that using inappropriate words and language, categorized as negotiation conflict in the present study, was placed in the emotional abuse category in this Japanese study. Several studies have identified similarly weak communication as a source of conflict $(13-15,31)$. In a previous study, Iranian women reported negotiation conflicts to be responsible for $97.1 \%$ of their conflicts (3). In Iranian society, women, especially in the first years of marriage, try very hard to perform all household chores on their own. In fact, the traditional patriarchal structure of the families considers women responsible for most activities in the house. Men, however, are mainly in charge of earning income (and maybe a little contribution in the housework). Since household chores and taking care of children are very demanding, Iranian women try hard to do their tasks completely and ideally. Hence, after several years of hard work in the house, they may suffer from physical and mental problems and seek medical and psychological help. Meanwhile, as such help (e.g., counseling) may not be in line with their traditional roles in the past years, more conflict may develop in the family. Many of the interviewees in the current research complained about mental and personal problems and consequences. Similar findings also have been reported in previous studies (15). Despite contextual and cultural differences of Iran and India, complaints about the heavy workloads in the house also were detected frequently in the statements of Indian women. While Iranian women emphasized the physical and mental consequences of conflict, Indian women reported the development of chronic diseases, tension, and mental stress (15). Furthermore, a group of Japanese women referred to health and mental/psychological problems as the outcomes of stress $(15,30)$. Likewise, Ennis showed that the burden of the family increased the risk of mental problems (32). Iranian women regarded various factors, one of which was different viewpoints, as causes of conflict in their marriages. David also reported different perspectives as an effective factor on long-term conflicts (13). Different expectations from marriages were suggested by Mukashema as another determinant of conflicts (31). Several interviewees in the present study highlighted the roles of other people in creating the conflicts in their lives. Previous research also has indicated similar findings (3, 13, 30, 31). Despite living away from their in-laws, Iranian couples seem to be under the influence of their parents' wills and their desired type of communication. Such an influence negatively affected some of the interviewees' lives and their relationships with their husbands. In fact, despite the industrialization and urbanization processes in the country, Iranian couples are still under the influence of their parents. According to some of the participants, exhaustion due to the load of household chores was another cause of their unhappiness. These women stated that financial problems forced their husbands to spend longer hours outside the house and return home very tired. This fatigue led to less communication with their wives. Various studies have examined the role of financial problems in creating conflicts among families $(13,14,31,33)$.

Iranian couples use different styles to resolve conflicts. Similar to the categorization provided by Thomas (34), four conflict resolution styles were identified in the present study (Kenneth Thomas proposed five styles). The Iranian women we studied tried to use interactive approaches, such as mutual conversations or counseling to resolve conflicts. If these mechanisms were successful, they continued this approach. In most cases, however, the husband's lack of collaboration or understanding obliged women to use other mechanisms, such as dominance, indifference, and sometimes accepting the situation. In fact, due to the stigmatization of divorce in the Iranian society, most couples preferred to protect their marriages, even using indifference or accommodation. Accepting the situation or accommodation was widely adopted by women either in the first years of their marriages or in the later stages. These strategies were implemented while the participants were actually willing to learn interactive and accommodation approaches. According to Abeya, women reacted differently to violence and conflict in the family, and these reactions included silence; embarrassment; looking for help from neighbors, acquaintances, and police; leaving the house; and self-defensive behaviors, such as beating and fighting back (29). Similar to our findings, Dildar reported that unsatisfied couples used the avoidance style more frequently than other mechanisms (14).

This study had several limitations. First, due to the large area of Tehran, this study was conducted only in the eastern and southeastern areas of the city so that the sample we used may not have represented all Iranian women, and, thus, the results cannot be generalized to all Iranian women. Second, only visitors to the health centers were interviewed, and this reduced the representativeness of the sample and the generalizability of the findings. Thus, further studies are needed of other housewives who do not visit such centers. Third, the participants of this study included only housewives, so the results are not generalizable to other women. Finally, the possibility of social acceptability bias of self-reported information cannot be ruled out. Despite the limitations of this study, there was an in-depth investigation about the real nature and depth of the phenomenon of conflict as well as its causes, consequences, and resolutions in Iranian women. The results may be beneficial in health promotion and counseling programs. We 
suggested that women identify some health centers with free or reasonable prices in order to consult psychologists or psychiatrists for their services. Also, we suggested that they attend and participate in free educational classes related to mental health, which are offered in the health centers.

\section{Conclusions}

Although Iranian women in our study might have been dissatisfied with their lives and well aware of the causes of conflict and cultural context of the society, they were most willing to protect their marriages. They even tried to protect their marriages by training their husbands to adopt the same behaviors. Hence, identifying the effective factors and approaches through further studies on men is suggested.

\section{Acknowledgments:}

This article was extracted from a Ph.D. thesis at Tehran University of Medical Sciences. We thank the University for funding this project with grant number 8921108002. Thanks to the health experts in the Health Centers of Tehran's municipality and the women who participated in this study.

\section{Conflict of Interest:}

There is no conflict of interest to be declared.

\section{Authors' contributions:}

All authors contributed to this project and article equally. All authors read and approved the final manuscript.

\section{References}

1) Koerner AF, Fitzpatrick MA. Family conflict communication; 2005:159-83. Available from: http://www.comm.umn.edu/ akoerner/My\%20pubs/Koerner\&Fitzpatrick_2006(Conflict_HB).pdf.

2) Cox F, Demmitt K. Human Intimacy: Marriage, the Family, and Its Meaning. 11 rd rev. ed. Canada: Cengage Learning; 2013.131.

3) Asadi Z, Moghaddam Hosseini V, Hashemian M, Akaberi A. Application of BASNEF Model in Prediction of Intimate Partner Violence (IPV) Against Women. The Journal of Asian Women. 2013;29(1):27-45.

4) Mahapatra N. South Asian Women in the U.S. and their Experience of Domestic Violence. J Fam Viol. 2012 April; 27(5):381-90. DOI: 10.1007/s10896-012-9434-4.

5) Yount KM, Li L. Domestic Violence Against Married Women in Egypt. Sex Roles. 2010 May; 63(56):332-47. DOI: 10.1007/s11199-010-9793-3

6) Ostenson JA, Zhang M. Reconceptualizing Marital Conflict: A Relational Perspective. Journal of Theoretical and Philosophical Psychology. 2014;34(4): 229-42. DOI: 10.1037/a0034517

7) Recker N. Dealing With Anger in a Marriage. The Ohio State University; 2010: 1. Available from: http://ohioline.osu.edu/hyg-fact/5000/pdf/5191.pdf

8) Fincham FD, Beach SRH. Marriage in the New Millennium: A Decade in Review. jomf. 2010 Jun; 72(3):630-49. DOI: 10.1111/j.1741-3737.2010.00722.x.

9) Whisman MA, Uebelacker LA. Prospective Associations Between Marital Discord and Depressive Symptoms in Middle-Aged and Older Adults. Psychol Aging. Mar 2009;24(1):184-9. doi: 10.1037/a0014759. PMID: 19290750

10) Fincham, Beach SRH. CONFLICT IN MARRIAGE: Implications for Working with Couples. Annu Rev Psychol. 1999;50:47-77. DOI: 10.1146/annurev.psych.50.1.47. PMID: 15012458

11) Holt-Lunstad J, Birmingham W, Jones BQ. Is there something unique about marriage? The relative impact of marital status, relationship quality, and network social support on ambulatory blood pressure and mental health. ann. behav. med. 2008 Apr;35(2):239-44. DOI: 10.1007/s12160-008-9018-y. PMID: 18347896

12) Gharehbaghy F, Aguilar-Vafaie M. The Role of Marital Conflict and Family Emotional Security in Children's Physical and Psychosocial Health. IJPCP. 2010 winter; 15(4):359-67.

13) David P. Research Findings on the Major Sources of Marital Conflict. Pair Bonding \& Repair: Essays on Intimacy \& Couple Therapy, 2014:28. Available from: http://pauldavidphd.com/wp-content/uploads/PairBonding-Repair.pdf

14) Dildar S, Sitwat A, Yasin S. Intimate Enemies: Marital Conflicts and Conflict Resolution Styles in Dissatisfied Married Couples. Middle-East J. Sci. Res. 2013; 15(10):1433-9. DOI: 10.5829/idosi.mejsr.2013.15.10.11581 
15) D’Souza MS, Karkada SN, Somayaji G, Venkatesaperumal R. Women's well-being and reproductive health in Indian mining community: need for empowerment. Reprod Health. 2013;10(24): 1-12. Doi: 10.1186/1742-4755-10-24. PMID: 23602071

16) Samani S. The Important Factors of Marital Conflict Between Married Students in Shiraz University. Journal of Family Research. 2008;3(3).657-68.

17) Kumar B, Singh AR. Relevance of Family Therapy in the Resolution of Family Dispute among Couple: Indian Perspective. The Qualitative Report. 2014;19:1-27.

18) Hajian A, Mohammadi S. The effect of training solution-focused couples therapy on dimensions of marital intimacy. Pak J Med Sci. 2013;29 (1)Suppl:321-324. doi: 10.12669/pjms.291(Suppl).3525

19) Arabnejad S, Birashk B, Abolmaali Alhossein K. The effectiveness of Acceptance and Commitment Therapy (ACT) on increasing Marital Intimacy and decreasing Marital. Journal of Social Issues \& Humanities. 2014;2(8):89-93.

20) Askari M, Noah SBM, Hassan SAB, Baba MB. Comparison the Effects of Communication and Conflict Resolution Skills Training on Marital Satisfaction. Int J Psychol Stud. 2012; 4(1):182-95. doi: 10.5539/ijps.v4n1p182.

21) Sharif F, Soleimani S, Mani A, Keshavarzi S. The Effect of Conflict Resolution Training on Marital Satisfaction in Couples Referring to Counseling Centers in Shiraz, Southern Iran. IJCBNM. 2013;1(1):2634.

22) Shahmoradi S, Fatehi Zade M, Ahmadi A. Prediction of marital conflict through the personality, psychological and demographic characteristics of spouses. Knowledge \& Research in Applied Psychology. 2011;12(1):33-44.

23) Heydari H, Sanaei Zakir B, Navabinejad S, Delawar A. Effect of effective dialogue (communication program couples CCP) to reduce marital conflict. Thoughts and behavior. 2009;4(14):15-24.

24) Mohsenzade F, Nazari A, Arefi M. A qualitative study of marital dissatisfaction and divorce action, (A case study in Kermanshah). Women's strategic studies. 2011;14(53):7-42.

25) Navidian A, Bahari F, Kermansaravi F. The Relationship of Interpersonal Conflict Handling Styles and Marital Conflicts Among Iranian Divorcing Couples. Glob J Health Sci. 2014;6(6): $245-51$. doi:10.5539/gjhs.v6n6p245. PMID: 25363128

26) Strauss AL, Corbin jM. Coding Procedures. 1998. In: Basics of Qualitative Research: Techniques and Procedures for Developing Grounded Theory. Sage Publications. 2 rd rev.ed. 1998; 101:121

27) Flick U. An introduction to qualitative research. SAGE. 4 rd rev.ed. 2009: 309-11.

28) Teddlie C, Tashakkori A. method and strategies of mixed methods research. foundations of mixed methods research. United States of America: SAGE publications; 2009: 295-6

29) Abeya SG, Afework MF, Yalew AW. Intimate partner violence against women in west Ethiopia: a qualitative study on attitudes, woman's response, and suggested measures as perceived by community members. Reprod Health. 2012;9(14):3-11. doi: 10.1186/1742-4755-9-14. PMID: 22906066

30) Nagae M, Dancy BL. Japanese women's perceptions of intimate partner violence (IPV). J Interpers Violence. 2010 Apr;25(4):753-66. doi: 10.1177/0886260509334413. PMID: 19465572

31) Mukashema I, Sapsford R. Marital Conflicts in Rwanda: Points of View of Rwandan Psycho-socio-medical Professionals. Procedia-Social and Behavioral Sciences. 2013;82:149-68. Doi: 10.1016/j.sbspro.2013.06.239

32) Ennis E, Bunting BP. Family burden, family health and personal mental health. BMC Public Health. 2013;13(255):1-9. doi: 10.1186/1471-2458-13-255. PMCID: PMC3607844

33) Madanian L, Mansor SMSS, Omar AHb. Marital Satisfaction of Iranian Female Students in Malaysia: A Qualitative Study. Procedia-Social and Behavioral Sciences. 2013; 84:987-993. doi: 10.1016/j.sbspro.2013.06.686

34) Thomas WK, Kilmann HR. TKI profile and interpretive report. CPP, Inc, 2008. Available from: http://www.kilmanndiagnostics.com/overview-thomas-kilmann-conflict-mode-instrument-tki 